\title{
Cardiovascular risk: a UK priority-it's time to act
}

C ardiovascular disease remains the main cause of death in the UK accounting for around four out of 10 of all deaths, more than 235000 deaths each year. ${ }^{1}$ Perhaps more importantly, it accounts for about $36 \%$ of premature deaths in men and $28 \%$ of premature deaths in women.

Despite a growing understanding of the pathophysiology and causes of cardiovascular disease, and an ever improving ability to treat it, this death toll is likely to continue rising worldwide.

Yet as the World Health Organization's World Health Report 2002 illustrates, more than $50 \%$ of deaths and disability from heart disease and strokes could be cut by a combination of simple, cost effective national efforts and individual actions to reduce major risk factors such as high blood pressure, high cholesterol, obesity, and smoking. ${ }^{2}$

"Cardiovascular risk: a UK priorityit's time to act" was the title of a one day conference held at the Royal College of Physicians that sought not only to highlight the problem of cardiovascular disease, but also to provide a forum for discussion of a range of issues pertinent to the current management of cardiovascular disease.

The meeting began by considering the multifactorial nature of cardiovascular disease and the concept of "global cardiovascular risk" as a means of targeting interventions to those patients most in need. This, of course, poses an immediate challenge to health care professionals, who have traditionally focused on managing cardiovascular risk factors in isolation. It also considered the need to tackle some of the less traditional but increasingly common cardiovascular risk factors such as smoking and obesity, which do not fall into any given specialty and are commonly seen as difficult to treat.

Much activity within the National Health Service is now subject to "targets" and cardiovascular disease is no exception. The meeting therefore considered the role of targets, whether individual or organisational, and the progress that has been made in achieving them. Certainly, recent years have witnessed a significant increase in the number of prescriptions written for the treatment and prevention of cardiovascular disease. But no matter how many prescriptions are written, drugs do not work in patients who do not take them. Therefore, the meeting considered what "cardiovascular risk" means to patients, and discussed some of the practical ways by which health care professionals can improve patients' compliance with medication.

Tackling cardiovascular disease in clinical practice represents an enormous agenda and one that is beyond the capability of any single professional group. Therefore, the conference placed great emphasis on interprofessional working, particularly on how doctors, nurses, and

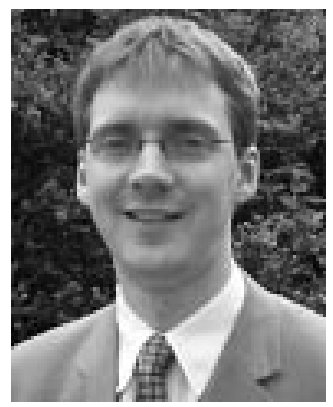

pharmacists can best work together for the benefit of patients.

Sharing experience of good practice in cardiovascular care plays a valuable role in "levelling up" services. The papers contained in this supplement are based on the presentations made at the meeting, and give a flavour of the discussions that took place.

Martin Cowie, Guest Editor

Cardiac Medicine National Heart \& Lung Institute, Faculty of Medicine, Imperial College Dovehouse Street, London SW3 6LY, UK m.cowie@imperial.ac.uk

\section{References}

1 British Heart Foundation Database. Coronary heart disease statistics, 2002 ed London: British Heart Foundation. Accessed 12 February 2003. URL: www.dphpc.ox.ac.uk/bhfhprg/stats/2000/ 2002/keyfacts/index.html

2 World Health Organization. World health report 2002: reducing risks promoting healthy life. Geneva: WHO, 2002. Accessed 13 February 2003. URL: www. who.int/whr/ 2002/en/

This supplement has been produced with the support of an unrestricted educational grant from Pfizer Ltd. The views expressed are those of the individual authors, and may or may not represent the views of Pfizer Ltd. 